\title{
Consumer Attitudes and Purchasing Interests of Coffee Shop which Implement Green Marketing and Non-Green Marketing in Malang, Indonesia
}

\author{
Livia Windiana ${ }^{1}$, M. Zul Mazwan ${ }^{1, *}$, and Gigin Mahdalena ${ }^{1}$ \\ ${ }^{1}$ Agribusiness Department, Faculty of Agriculture and Animal Science, University of \\ Muhammadiyah Malang, Indonesia
}

\begin{abstract}
There are many universities in Malang. This has an impact on increasing the number of newcomers to stay and invest in Malang, one of which is a coffee shop. This has the potential to cause a lot of waste due to the production of coffee drinks. Green Marketing is an effort by the government and coffee drink producers to minimize waste caused by the coffee industry. This study aims to 1) analyzing differences in consumer attitudes towards coffee shops that implement green marketing and nongreen marketing strategies; 2) Determine whether there is a relationship between attitudes and consumer purchase intention towards coffee drink products in coffee shops that implement Green Marketing and non-green marketing strategies. The analytical method uses Fishbein analysis and the Spearman Rank test. Questionnaire was given to 100 respondents at Starbucks and 100 respondents at Pesen Kopi in Malang. The results show that consumers have a positive attitude towards coffee shops that implement green marketing, and consumers have a negative attitude towards coffee shops that implement non-green marketing. The results also show a strong positive correlation between green marketing strategies and customer purchase intention for environmentally friendly coffee drink products.
\end{abstract}

\section{Introduction}

One of the businesses that are widely developed and in demand in Malang is the Coffee Shop business. Coffee shops are increasingly resulting in the potential for a lot of waste caused by instant coffee packaging, plastic cups, plastic straws and others. Finally, the careless use of these chemicals will cause global environmental damage [1]. [2] said that then sparked global attention and also gave birth to an environmentally friendly movement which is now considered to be influencing many sectors in Indonesia and invites to do the same, both from government, researchers, business, consumers and others. The Indonesian government in this regard has developed and introduced environmentally oriented policies. February 2016, the Government of Indonesia through the Ministry of Environment and Forestry established a new policy regarding the use of plastic bags in the retail industry

\footnotetext{
* Corresponding author: mzulmazwan@umm.ac.id
} 
such as supermarkets and hypermarkets. Many marketers and companies now use environmental issues as a way to attract public interest and company image $[3,4]$. One of the ways is through the implementation of green marketing as a marketing strategy as well as an environmentally friendly marketing management. Green marketing is carried out by the company as the company's responsibility for the environment as well as to meet the needs and desires of consumers for environmentally friendly products.

Indonesian researchers have started to conduct research related to this phenomenon and publish their findings to the public. Previous research conducted in Indonesia related to the consumption of environmentally friendly products, focused more on research on the factors that influence the buying behavior of environmentally friendly products $[1,5,6,7,3,8,9$, $4,10,11,12]$. Many coffee consumers today are also starting to become aware of and participate in this green activity, such as starting to buy reusable packaging that has been provided in several coffee shops and also purchasing stainless straws to reduce straw waste and also purchasing plastic packaging. Based on this description, the researchers compared the differences in consumer attitudes towards the implementation of green marketing and non-green marketing and analyzed consumer buying interest towards coffee beverage products in coffee shops that implemented green marketing and non-green marketing strategies. According to $[13,14]$ this continues how marketers and governments can help consumers behave more responsibly through compliance and commitment to environmentally friendly marketing strategies (products, prices, promotions, and places or distribution).

\section{Research Methods}

The determination of the research location was carried out purposively, namely in one of the coffee shops that implemented a green marketing strategy in the city of Malang, Indonesia, namely "Starbucks" in the Araya area and as a comparison for coffee shops that did not implement green marketing, namely "Pesenkopi" in Sigura-gura area in December 2019 - February 2020. The sampling method used in this study was convenience sampling with a sample size of 200 respondents at each coffee shop. The number of samples is 200 divided by the number of shops studied, 100 respondents in the coffee shop "Starbucks" and 100 respondents in the coffee shop "Pesenkopi".

\subsection{Attitude Analysis (Fishbein Analysis)}

Consumer attitudes towards product attributes can be determined based on the level of trust, where these attributes will be evaluated and given a weighted value. Attitude measurement is done by measuring all attributes (multi-attribute) with the formula:

$$
A o=\sum(b i x e i)
$$

Where: Ao $=$ attitude towards coffee shop

$\mathrm{bi}=$ consumer confidence in the attributes of the coffee shop

ei $=$ consumer evaluation of the attributes of the coffee shop

$\sum=$ addition of a number of attributes ( 4 attributes)

The attributes of the confidence and attitude evaluation variables are green product, green price, green place and green promotion, each of which has several indicators. 
Table 1. Confidence and Evaluation Criteria

\begin{tabular}{|c|c|c|}
\hline Range of Value & Confidence level & Evaluation level \\
\hline-1.21 to -2.00 & Strongly Disagree & Very Bad \\
\hline-0.41 to -1.20 & Disagree & Bad \\
\hline-0.40 to 0.40 & Neutral & Doubt \\
\hline 0.41 to 1.20 & Agree & Good \\
\hline 1.21 to 2.00 & Strongly Agree & Very Good \\
\hline
\end{tabular}

\subsection{Measure Differences in Attitudes (Mann-Whitney Analysis)}

The measurement used to determine whether there is a difference in response or consumer attitudes in the implementation of green marketing coffee shops and non-green marketing coffee shops, namely by using the Mann-Whitney test on an ordinal scale. The Mann-Whitney test is used to compare consumer attitudes to coffee shops that implement green marketing and non-green marketing.

\subsection{Relationship between Attitude and purchase intention (Rank Spearman Correlation Analysis)}

Measuring variables to determine whether there is a relationship between overall attitudes and purchase intention can be measured using the Rank Spearman Correlation test. Formula:

$$
r_{s}=1-\frac{6 \sum d^{2}}{n^{3}-n}
$$

Where:

$\mathrm{d}=$ deviation of $\mathrm{X}$ and $\mathrm{Y}$ ranks

$\mathrm{n}=$ number of data

\section{Result and Discussions}

Based on the validity test and reliability test on all green marketing and non-green marketing research data, it is significant at the $5 \%$ significance level.

\subsection{Analysis of Attitudes}

Attitudes towards coffee shops implementing Green Marketing in this study are assessed from 4 attributes, namely green product, green price, green place and green promotion. Table 2 shows that consumer attitudes at Starbucks coffee shops are predominantly positive. The attribute green place question number $8 \&$ promotion number 11 is the best attribute of several other attributes with the highest average value of confidence and evaluation, namely $1.84 \& 1.93$ (strongly agree). This shows that consumers like furniture with recycled materials used by Starbucks in its stores. Consumers can be said to be natural if they like this because the Starbucks coffee shop is a shop that applies green marketing to its marketing strategy, besides that consumers also definitely like products that are safe and friendly to consumers and the environment. The results of this study are consistent with research by $[6,15,16]$ which states that most consumers have a positive attitude and have expressed great interest in environmental protection and environmentally friendly products, especially Starbucks.

Consumers strongly agree with an average of 1.76 on the green product attribute, which means that products that use recycled packaging are good products. Most consumers 
think that they strongly agree with the green products that have been provided by Starbucks. The green product attribute is considered very good on the evaluation variable with an average of 1.79 by consumers because it uses Tumbler packaging which reduces waste besides being friendly and safe for consumers and the environment. [17, 2] assert that people who are more concerned about their health are more likely to buy environmentally friendly products.

Table 2. Attitudes of Respondents toward Starbucks Coffee Shops

\begin{tabular}{|c|c|c|c|c|}
\hline \multirow{2}{*}{ Attribut } & Confidence (bi) & $\begin{array}{c}\text { Evaluation } \\
(\mathbf{e i})\end{array}$ & $\begin{array}{c}\text { Attitude } \\
(\mathbf{b i}) \mathbf{x}(\mathbf{e i})\end{array}$ & Consummer Attitude \\
\hline \multirow{3}{*}{ Green Product } & 1.76 & 1.80 & 3.16 & Very Positive \\
\cline { 2 - 5 } & 1.76 & 1.76 & 3.09 & Very Positive \\
\cline { 2 - 5 } & 1.76 & 1.77 & 3.11 & Very Positive \\
\cline { 2 - 5 } Green Price & 1.82 & 1.66 & 3.02 & Very Positive \\
\cline { 2 - 5 } & 1.76 & 1.67 & 2.93 & Very Positive \\
\cline { 2 - 5 } & 1.80 & 1.78 & 3.20 & Very Positive \\
\hline \multirow{2}{*}{ Green Place } & 1.67 & 1.79 & 2.98 & Very Positive \\
\cline { 2 - 5 } & 1.83 & 1.84 & 3.36 & Very Positive \\
\hline \multirow{2}{*}{ Green Promotion } & 1.84 & 1.81 & 3.33 & Very Positive \\
\cline { 2 - 5 } & 1.78 & 1.75 & 3.11 & Very Positive \\
\hline \multicolumn{2}{|c|}{ Total } & 1.93 & 3.47 & Very Positive \\
\hline
\end{tabular}

Source: Collected and calculated from primary data

In the confidence variable, namely the green promotion attribute with an average value of 1.81, which means that consumers like products and advertisements that are committed to the environment. This is in line with the evaluation variable which shows that the Green Promotion attribute gets the highest average value, meaning that advertisements that convey messages about the environment and have a commitment to the environment are good things and make consumers interested. Indirectly, advertising on Starbucks invites consumers to be aware of the environment. The green price attribute is also considered good and consumers agree that the price they pay includes maintenance costs and for environmental preservation. According to consumers, they have no problem with the price offered as long as they get the green green product they want. Green Promotion and green price are also given very good values and consumers also strongly agree when there are promos and discounts which of course make green products that are environmentally friendly at the price offered very easy to reach, and it means that respondents also like Starbucks advertisements with their commitment to the environment.

Consumer attitudes towards Starbucks coffee shops are 34.82 or respondents as a whole are positive towards all the specified attributes. The highest attitude is found in the green promotion attribute affecting decision making in purchasing at Starbucks coffee shops with an attitude value of 3.11 and 3.47, which means that advertisements displayed by Starbucks are the first consideration in influencing consumer attitudes towards green marketing coffee shops. The next attribute that also affects consumer attitudes in purchasing at Starbucks coffee shops is the green place attribute with an attitude value of 3.36, which means that consumers in their assessment also consider the state of the place that makes them comfortable and safe because of the environmental concept that has been displayed by the Starbucks coffee shop.

Then followed by the green product attribute with an attitude value of 3.11 , which means that consumers like and begin to consider environmentally friendly products offered by Starbucks Coffee. The green price attribute occupies the lowest position with an attitude 
value of 3.02, which means that the price offered is not a problem for consumers as long as consumers get the benefits according to their wishes.

The results of the value of consumer attitudes at non-green marketing coffee shops can be seen in Table 3 below:

Table 3. Attitudes of Respondents toward the Pesenkopi Coffee Shop

\begin{tabular}{|c|c|c|c|c|}
\hline \multirow{2}{*}{ Attribut } & $\begin{array}{c}\text { Convidence } \\
(\mathbf{b i})\end{array}$ & $\begin{array}{c}\text { Evaluation } \\
(\mathbf{e i})\end{array}$ & $\begin{array}{c}\text { Attitude } \\
(\mathbf{b i}) \mathbf{x}(\mathbf{e i})\end{array}$ & $\begin{array}{c}\text { Consummer } \\
\text { Attitude }\end{array}$ \\
\hline \multirow{2}{*}{ Non Green Product } & 0.39 & -1.1 & -0.4 & Sufficient \\
\cline { 2 - 5 } & -1 & -1.4 & 1.4 & Positive \\
\hline \multirow{2}{*}{ Non Green Price } & 0.69 & 0.09 & 0.06 & Sufficient \\
\cline { 2 - 5 } & -0.1 & -0.4 & 0.04 & Sufficient \\
\hline \multirow{2}{*}{ Non Green Place } & 0.18 & -0.5 & -0.1 & Negative \\
\cline { 2 - 5 } & -0.6 & -0.2 & 0.12 & Sufficient \\
\hline Non Green Promotion & 0.55 & -0.5 & -0.3 & Sufficient \\
\hline & Total & & $\mathbf{0 . 8 2 8}$ & \\
\hline
\end{tabular}

Source: Collected and calculated from primary data

Table 3 shows that consumers tend to be negative towards non-green marketing coffee shops, which means that they are aware of and do not like products that are not committed to the environment. The non-green product attribute variable consumer confidence responds with a neutral attitude and disagrees with an average value of 0 to -1 for Non Green Marketing products. In the opinion of consumers they disagree with products that use disposable or reusable packaging because it will pollute the environment, and consumers who give a neutral assessment they think that plastic packaging, plastic straws and plastic bags are practical for them regardless of whether it is dangerous for the surrounding environment. $[18,8]$ stated that environmentally friendly products are considered by consumers to be too expensive, too time-consuming (in terms of obtaining knowledge or product location), or too difficult to obtain.

The non-green price attribute in the Confidence variable shows an average value of -1 and 0.69 with a neutral attitude and agrees with the price offered by non-green products, while the consumer evaluation variable gives doubtful assessments with an average value of 0.09 and -0.4 which means that consumers think that it is okay to get the product and the benefits of the product at the price offered by the Pesenkopi coffee shop. The confidence variable in the non-green place attribute is assessed as neutral by an average of 0.18 to -0.6 by consumers, as well as the consumer evaluation variable assessing it with -0.5 to -0.2 which means that consumers are hesitant about the choice of concept. The take away chosen by Pesenkopi will certainly cause the potential for plastic waste to spread due to the packaging, straws and bags used by the Pesenkopi coffee shop.

The non-green promotion attribute on the consumer confidence variable shows an average of 0.55 with a positive attitude or consumers agree with this attribute, which means that there is no effect when the Pesenkopi coffee shop presents their advertisements, consumers continue to buy and consume non-green marketing products regardless of benefits and impact on the environment. The evaluation variable also shows the attitude of consumers who are hesitant on Pesenkopi advertisements that do not display advertisements about the environment and do not display a message calling for consumers to care about the environment. Consumers are aware that companies need to implement advertising promotions about socially beneficial behavior change. The emphasis is on issues related to health, environment, children, and human dignity $[11,17,19]$.

The attitude of respondents towards the Pesenkopi coffee shop is dominated by attributes of non-green product, non-green promotion and non-green place with values ($0.4),(-0.3)$ and $(-0.1)$ with quite positive attitudes, this is in line with research at Starbucks 
(green marketing) that friendly products, advertisements that are committed to the environment and a comfortable place with a natural concept displayed will affect consumer ratings of the coffee shop.

\subsection{Differences in Consumer Attitudes}

Different test research to determine differences in consumer attitudes towards the implementation of green marketing and non-green marketing at Starbucks and Pesenkopi coffee shops can be seen by testing the average value of consumer attitudes at each Starbucks and Pesenkopi stores. In this study, the U-test was carried out at a significant level of $\alpha=0.05$ with a confidence level of $95 \%$. This Mann Whitney U-test calculation uses the help of IBM SPSS software. The data from the U-test calculation results from Mann Whitney can be seen in Table 13 below:

Table 4. Result of U-Test Calculation from Mann Whitney on Coffee Shop Respondents Implementation of Green Marketing

\begin{tabular}{|l|r|}
\hline \multicolumn{1}{|c|}{ Result of U-Test } & \multicolumn{1}{c|}{ Value of Total Attitude } \\
\hline Mann-Whitney U & 13,000 \\
\hline Wilcoxon W & 5063,000 \\
\hline Z & -12.197 \\
\hline Asymp. Sig. (2-tailed) & .000 \\
\hline
\end{tabular}

Source: Collected and calculated from primary data

Based on "Test Statistics" it is known that the Asymp. Sig. (2-tailed) of $0.000<0.05$, which means that there can be differences in attitudes between consumers at Starbucks and Pesenkopi coffee shops. The results showed that consummer attitudes towards the coffee shop implementation of green marketing Starbucks was different from the attitude towards non-green marketing coffee shop Pesenkopi. Consumers tend to be positive towards green marketing products and neutral towards non-green marketing products. This is in line with the research of [20] which states that environmentally friendly consumers when compared to non-green consumers have an attitude that prefers the environment. Green consumers are more socially integrated, open-minded, and cosmopolitan [7]. Today more and more people are willing to pay extra for environmentally friendly products, as long as they provide the same satisfaction and convenience compared to non-green marketing products $[17,10,21]$.

\subsection{The Relationship between Consumer Attitude and Purchase Intention}

The research analysis of the relationship between the variables of attitude and purchase intention was tested using the Spearman Rank correlation test to determine the closeness of the relationship between the ordinal variables. Based on the analysis using the IBM SPSS analysis application, the results of the analysis are obtained in Table 14 below:

Table 5. Result of Rank Spearman Correlation Test

\begin{tabular}{|c|c|c|c|c|}
\hline \multirow{2}{*}{\begin{tabular}{|l|} 
Spearman's rho \\
\end{tabular}} & & & Attitude & Purchase Intention \\
\hline & \multirow[t]{3}{*}{ Attitude } & Correlation Coefficient & 1.000 & $.761^{* *}$ \\
\hline & & Sig. (2-tailed) & & .000 \\
\hline & & $\mathrm{N}$ & 200 & 200 \\
\hline & \multirow{3}{*}{\begin{tabular}{|l} 
Purchase \\
Intention
\end{tabular}} & Correlation Coefficient & $.761^{* *}$ & 1.000 \\
\hline & & Sig. (2-tailed) & .000 & \\
\hline & & $\mathrm{N}$ & 200 & 200 \\
\hline
\end{tabular}

Source: Collected and calculated from primary data 
The results of the Spearman rank correlation analysis found a significant correlation between attitude and purchase intention where $0.00<0.05$, which means that $\mathrm{H} 0$ is rejected and $\mathrm{H} 1$ is accepted or there is a relationship between the attitude variable and purchase intention variable. The table above also shows that the correlation coefficient value is 0.761, which means that the direction of the relationship between the attitude and purchase intention variables is a very strong correlation and the correlation is positive, so that the relationship between consumer attitude variables and consumer purchase intention in coffee shops that implement green marketing is unidirectional. It also can be interpreted that the higher the consummer attitude, the more interest in buying consumers will also increase.

This study also shows that attitudes also have a relationship with consumer purchase intention from the results which show similarities to previous research conducted by [22] which states that attitudes, norms, and control of consumer behavior contribute positively to purchase intention. The results of this study are also in line with the opinion [12] which states that Consumer Attitudes towards Consumer Intention to Buy Smartphones which are carried out always provide positive contribution to attitude to buying. To encourage the implementation of environmentally friendly living, companies must promote green branding strategies, environmentally friendly labeling, and environmentally friendly packaging to encourage environmentally friendly consumption patterns by consumers [6] [23]. Marketers need to adopt and apply sustainable marketing principles, namely the implementation of green marketing [18]. So that it will have an impact on the attitudes and environmental values of consumers in a responsible manner and high interest in buying environmentally friendly products [24].

\section{Conclusions}

Based on the results of the analysis, it is concluded that consumer attitudes are very positive towards Starbucks coffee shops (green marketing). Consumers have a neutral attitude towards Pesenkopi coffee shop (non green marketing). Respondents' responses indicate that there are significant differences in attitudes between consumers at green marketing and non-green marketing coffee shops. There is a very strong and positive correlation between attitude and purchase intention. Like the results obtained from research, green marketing has a positive impact on consumer attitudes so that it should be maintained and applied to coffee shops in particular and can be considered for application in various industries in general.

\section{References}

1. J. Rana and J. Paul, J. Retail. Consum. Serv. 38, 157 (2017).

2. R. M. Dangelico and D. Vocalelli, J. Clean. Prod. 165, 1263 (2017).

3. J. J. Cronin, J. S. Smith, M. R. Gleim, E. Ramirez, and J. D. Martinez, J. Acad. Mark. Sci. 39, 158 (2011).

4. J. F. Kirchoff, C. Koch, and B. S. Nichols, Int. J. Phys. Distrib. Logist. Manag. 41, 684 (2011).

5. A. Osman, Y. H. Othman, S. N. Salahudin, and M. S. Abdullah, Procedia Econ. Financ. 35, 428 (2016).

6. T. Devi Juwaheer, S. Pudaruth, and M. Monique Emmanuelle Noyaux, World J. Entrep. Manag. Sustain. Dev. 8, 36 (2012).

7. I. Confente, D. Scarpi, and I. Russo, J. Bus. Res. 112, 431 (2020).

8. C. Groening, J. Sarkis, and Q. Zhu, J. Clean. Prod. 172, 1848 (2018). 
9. Z. Hasan and N. A. Ali, Procedia - Soc. Behav. Sci. 172, 463 (2015).

10. Q. Zhu and J. Sarkis, Int. J. Prod. Econ. 181, 289 (2016).

11. M. B. Royne, J. Thieme, M. Levy, J. Oakley, and L. Alderson, J. Bus. Strategy 37, 37 (2016).

12. P. Kumar, Mark. Intell. Plan. 34, 137 (2016).

13. P. Kumar and M. J. Polonsky, Australas. Mark. J. 25, 85 (2017).

14. P. Kumar, World J. Entrep. Manag. Sustain. Dev. 11, 176 (2015).

15. J. Majerova, Procedia Econ. Financ. 26, 553 (2015).

16. M. F. Chen and C. L. Lee, Br. Food J. 117, 195 (2015).

17. L. Kwok, Y. K. Huang, and L. Hu, Int. J. Hosp. Manag. 55, 107 (2016).

18. L. P. Tan, M. L. Johnstone, and L. Yang, Australas. Mark. J. 24, 288 (2016).

19. H. H. Zhao, Q. Gao, Y. P. Wu, Y. Wang, and X. D. Zhu, J. Clean. Prod. 63, 143 (2014).

20. S. A. Narula and A. Desore, Soc. Responsib. J. 12, 1 (2016).

21. K. C. Chang, C. L. Hsu, Y. T. Hsu, and M. C. Chen, J. Retail. Consum. Serv. 49, 336 (2019).

22. Y. Sun and S. Wang, Asia Pacific J. Mark. Logist. 32, 860 (2019).

23. A. A. Bailey, A. Mishra, and M. F. Tiamiyu, J. Consum. Mark. 33, 562 (2016).

24. U. Aagerup and J. Nilsson, J. Prod. Brand Manag. 25, 274 (2016). 